\title{
Effect of Rice Husk ash and Fly ash Reinforcements on Microstructure and Mechanical properties of Aluminium alloy (AISi10Mg) Matrix Composites
}

\author{
A. P. S. V. R. Subrahmanyam ${ }^{1}$, G. Narsaraju ${ }^{2}$ and B. Srinivasa Rao ${ }^{3}$ \\ ${ }^{I}$ Assistant professor, Dept. of Mechanical Engineering, BVC College of Engineering, \\ Rajahmundry, AndhraPradesh, India \\ ${ }^{2}$ Associate Professor, Dept. of Mechanical Engineering, BVC Engineering College, \\ Odalarevu, Andhra Pradesh, India \\ ${ }^{3}$ Associate Professor, Dept. of Mechanical Engineering, BVC Engineering College, \\ Odalarevu, Andhra Pradesh, India \\ Corresponding Author: e-mail: subbuaynavilly@gmail.com
}

\begin{abstract}
The application spectrum of low cost material reinforced metal matrix composites is growing rapidly in various engineering fields due to their superior mechanical properties. In the present study aluminium alloy (AlSilOMg) is reinforced with locally available inexpensive rice husk ash(RHA) and fly ash(FA) for developing a new hybrid composite material. A rice husk ash and fly ash particles of 5, 10 and 15\% each by weight are added to develop metal matrix composites using liquid metal processing route. The surface morphology was studied using scanning electron microscope. The mechanical properties such as tensile strength, hardness and percentage elongations were studied for the all test specimens.
\end{abstract}

Keywords: Hybrid Composite material, Mechanical properties, SEM

\section{Introduction}

In the last two decades, research has shifted from monolithic materials to composite materials to meet the global demand for light weight, high performance, environmental friendly, wear and corrosion resistant materials. Aluminium metal matrix composites (AMMCs) have considerable applications in aerospace, automotive and military industries due to their high strength to wear ratio, stiffness, light weight, good wear resistance and improved thermal and electrical properties. Ceramic particles such as $\mathrm{Al}_{2} \mathrm{O}_{3} \mathrm{SiC}$ are the most widely used materials for reinforcement of aluminium. Rice husk and Fly ash could be an alternative to $\mathrm{SiC}$ and $\mathrm{Al}_{2} \mathrm{O}_{3}$ due to their availability in large quantity. Rice husk and Fly ash have attractive properties like high strength, extremely high hardness, good wear resistance, low coefficient of friction, high thermal conductivity and also contains excellent machinability.

Rice husk is an agricultural residue which accounts for $20 \%$ of the 649.7 million tons of rice produced annually worldwide. This RHA is a great environment threat causing damage to the land and the surrounding area in which it is dumped. This ensures the researcher for effective utilization of this agricultural waste.Burning the husk under controlled temperature below $800{ }^{\circ} \mathrm{C}$ can produce ash with silica mainly in amorphous form, which can produce the composites with low density and having high temperature resistance and hardness.

Fly ash is one of the residues generated in the combustion of coal. It is an industrial byproduct recovered from the flue gases of coal burning in electric power plants. Depending 
upon the source and makeup of the coal being burned, the components of the fly ash produced vary considerably, but all fly ash includes substantial amounts of silica (silicon dioxide, $\mathrm{SiO}_{2}$ ) (both amorphous and crystalline) and lime (calcium oxide, $\mathrm{CaO}$ ). The high electrical resistivity, low thermal conductivity and low density of fly-ash may be helpful for making a light weight insulating composites.

Stir casting is the most popular commercial method of producing aluminum based composites.In this method, pre heated ceramic particulates are incorporated into the vortex of the molten matrix created by a rotating impeller. In principle, it allows a conventional metal processing route to be used, and hence minimizes the final cost of the product.

In the present work, rice husk ash and fly ash particles of 5,10 and $15 \%$ each by weight were added to Al6061 alloy (AlSi10Mg) through Stir casting to produce hybrid composite. The Surface morphology and mechanical properties were studied for the resulted hybrid composite.

\section{Literature Review}

[1] S. D. Saravanan, M. Senthil Kumar studied the properties of the AlSi10Mg /RHA composite and found that the Tensile Strength, Compression Strength and Hardness of the metal matrix composite increases and ductility gets decrease with increase in the weight fraction of rice husk ash.

[2] S. Sarkar S. Tripathy, S. Mohan concluded that the Ultimate tensile strength has improved where as ductility has decreased with increase in fly ash content to Al-Si and Al$\mathrm{Mg}$ alloys.

[3] H.C. Anilkumar, H.S. Hebbar and K.S. Ravishankar found that the stir casting method used to prepare the composites could produce uniform distribution of the reinforced fly ash particles. The Tensile Strength, Compression Strength and Hardness increased with the increase in the weight fraction of reinforced fly ash and decreased with increase in particle size of the fly ash. The ductility of the composite decreased with increase in the weight fraction of reinforced fly ash and decreased with increase in particle size of the fly ash. The enhancement in the mechanical properties can be well attributed to the high dislocation density.

[4] Satish D, Kene, Pravin V. Domke, Sandesh D. Deshmukh, R.S.Deotale., did "Assessment of Concrete Strength using Fly ash and Rice husk ash" and they concluded that rice husk when burned produced amount of silica (more than 80\%). For this reason it provides excellent thermal insulation. The workability of RHA concrete has been found to decrease but FA increases the workability of concrete. Compressive strength increases with the increase in the percentage of Fly ash and Rice Husk Ash up to replacement.

[5] D. Siva Prasad, Dr .A. Rama Krishna concluded the hardness of A356.2/RHA composites increases with increase in rice husk ash content. Incorporation of rice husk ash particles in aluminium matrix can lead to the production of low cost aluminium composites with improved hardness and strength.

\section{Experimental Procedure}

\subsection{Materials}

For the present experimental investigation, AlSi10Mg aluminum (6061) alloy was used as a matrix material whose chemical composition (in wt \%) is listed in Table 1 . AlSi10Mg is a typical casting alloy with good casting properties. Fiber reinforcements rice husk ash and fly ash chemical composition (in wt \%) are listed in Table 2 and 3. 
Table 1. Chemical Composition of the Matrix Alloy (\%Wt)

\begin{tabular}{|c|c|c|c|c|c|c|c|c|c|c|}
\hline $\begin{array}{c}\text { Chemical } \\
\text { Composition }\end{array}$ & $\mathrm{Cu}$ & $\mathrm{Si}$ & $\mathrm{Fe}$ & $\mathrm{Mn}$ & $\mathrm{Ni}$ & $\mathrm{Zn}$ & $\mathrm{Pb}$ & $\mathrm{Sn}$ & $\mathrm{Ti}$ & $\mathrm{Al}$ \\
\hline$\%$ & 0.1 & $\begin{array}{c}10.0- \\
13.0\end{array}$ & 0.6 & $\begin{array}{c}0.3- \\
0.7\end{array}$ & 0.1 & 0.1 & 0.1 & 0.05 & 0.2 & $\begin{array}{c}\text { Bala } \\
\text { nce }\end{array}$ \\
\hline
\end{tabular}

Table 2. Chemical Composition of Rice Husk Ash ( \%Wt)

\begin{tabular}{|c|c|c|c|c|c|c|c|c|}
\hline $\begin{array}{c}\text { Chemical } \\
\text { Composition }\end{array}$ & $\mathrm{SiO}_{2}$ & $\mathrm{Al}_{2} \mathrm{O}_{3}$ & $\mathrm{Fe}_{2} \mathrm{O}_{3}$ & $\mathrm{Cao}$ & $\mathrm{MgO}$ & $\mathrm{N}_{2} \mathrm{O}$ & $\mathrm{K}_{2} \mathrm{O}$ & LOI \\
\hline$\%$ & 94.04 & 0.249 & 0.136 & 0.622 & 0.442 & 0.023 & 2.49 & 3.52 \\
\hline
\end{tabular}

Table 3. Chemical Composition of Fly Ash ( \%Wt)

\begin{tabular}{|c|c|c|c|c|c|}
\hline Chemical Composition & $\mathrm{Al}_{2} \mathrm{O}_{3}$ & $\mathrm{SiO}_{2}$ & $\mathrm{Fe}_{2} \mathrm{O}_{3}$ & $\mathrm{TiO}_{2}$ & LOI \\
\hline$\%$ & 28.44 & 59.96 & 8.85 & 2.75 & 1.43 \\
\hline
\end{tabular}

\subsection{Composite Preparation}

The sequential procedure followed in the fabrication of hybrid composite is as follows. Heat the AlSi10Mg alloy pieces in the furnace till melts at $750^{\circ} \mathrm{C}$ and care is taken to achieve $100 \%$ melting. Slag is removed using scum powder to avoid the bad quality of casting. Take less than $5 \%$ weight of solid dry hexa-chloro-Methane tablets to degas the molten alloy at a temperature of $780^{\circ} \mathrm{C}$. Measure the $15 \%, 10 \%$ and $5 \%$ of fly ash (reinforcement) by weight and rice husk ash of $5 \%, 10 \%$ and $15 \%$ by weight separately and are pre heated to $450{ }^{\circ} \mathrm{C}$ $600^{\circ} \mathrm{C}$ and maintained at the same temperature for about 20 minutes to remove the moisture content. Now start stirring the molten alloy to create a vortex. Add slowly pre heated fly ash $15 \%$, rice husk ash $5 \%$ to the molten alloy with temperature maintained at more than $720^{\circ} \mathrm{C}$. Add magnesium about $2 \%$ of weight to ensure good wettability for all proportions of the reinforcements with continuous stirring at a speed of 350-500 rpm to a time of 6-8 minutes. Meanwhile preheat the mould to avoid shrinkage of casting material. Then the melted matrix and reinforced particles is poured into the preheated mould and the pouring temperature should be maintained at $680^{\circ} \mathrm{C}$.Repeat the same procedure for the other two combinations of the reinforcements (i.e., 10\% FA+ 10\%RHA and 5\% FA+ 15\%RHA) by keeping alloy (AlSilOMg), and magnesium ( $\mathrm{Mg})$ as constant in weight. Finally withdraw the specimens from the mould after complete cooling. And confirm the solidification of casting before removing from the mould.

\section{Results and Discussion}

\subsection{Microstructure Analysis}

The micro structure plays an important role for analyzing the distribution of distinct phases in an Aluminium matrix material. The micro structure was studied by using scanning electron microscope and which shows that the phases are near uniformly distributed in the metal matrix. And the SEM Images of the three specimens were as shown below. 


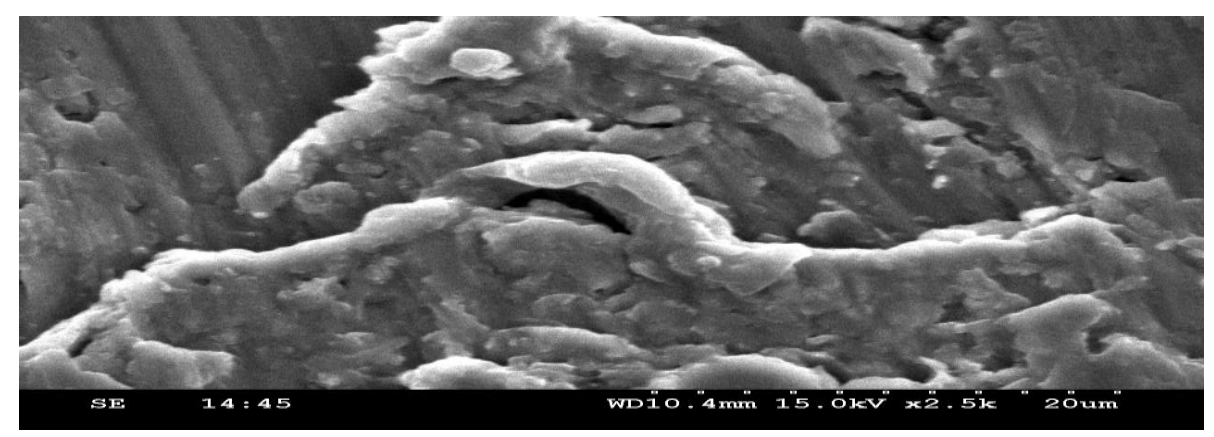

Figure 4.1. (a) AlSi10Mg +15\% FA+5\% RHA

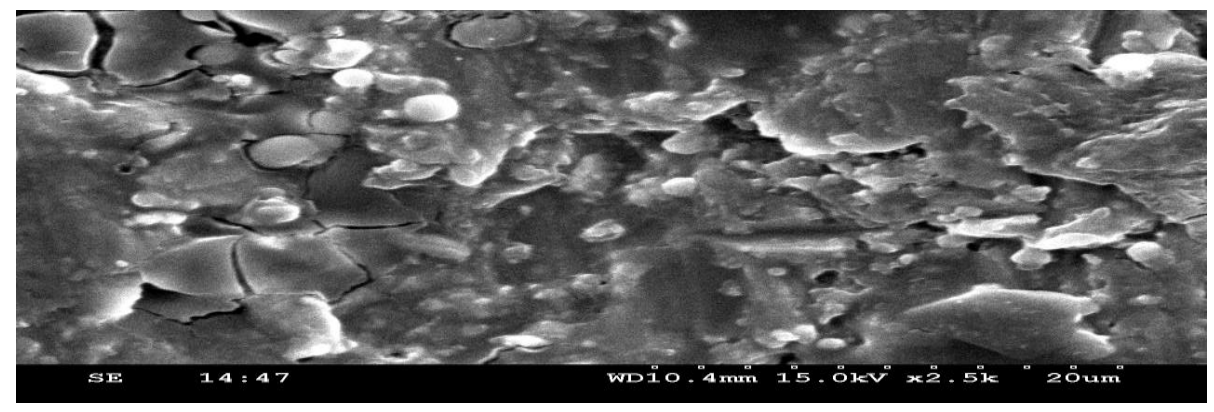

Figure 4.1. (b) AISi10Mg + 10\% RHA +10\% FA

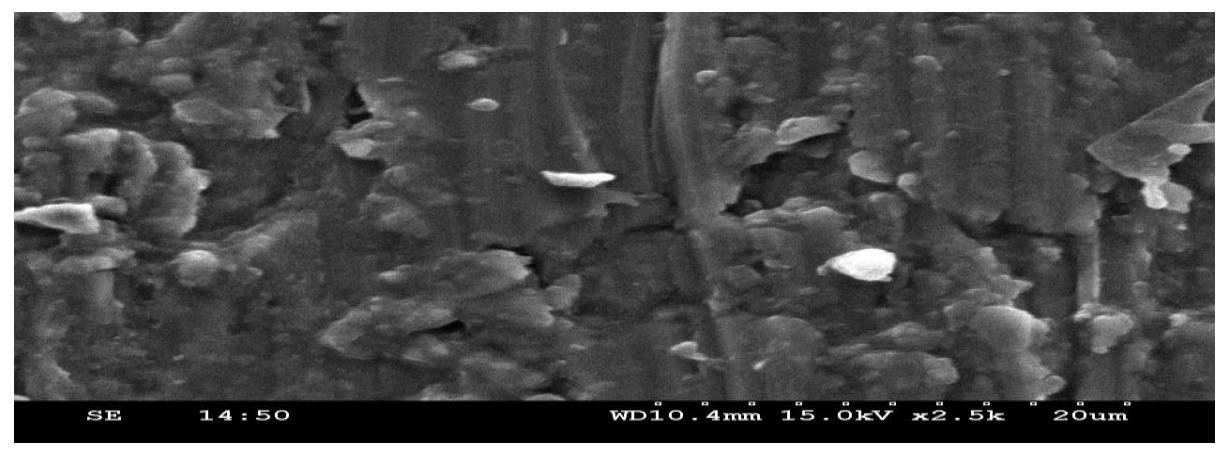

Figure 4.1. (c) AlSi10Mg + 15\% RHA +5\% FA

The SEM micrographs of Al-Si10Mg/Rice Husk Ash/Fly Ash hybrid composites are shown in Figure 4.1(a) to 4.1(c).

The size, density, type of reinforcing particles, and its distribution have a pronounced effect on the properties of particulate composites. The variables affecting the distribution of particles are solidification rate, fluidity, type of reinforcement, and the method of incorporation. It is essential to get particles uniformly throughout the casting during particulate composite production. The first task is to get a uniform distribution of particles in the liquid melt and then to prevent segregation/agglomeration of particles during pouring and progress of solidification. One of the major requirements for uniform distribution of particles in the melt is its wettability.

RHA has the appearance of fiber-reinforced flakes while FA has the morphology of hollow spheres, some of them with manifest pores. Rice husk ash and fly ash particles were successfully incorporated in AlSi10Mg (matrix) alloy by using stir casting technique. Micro structure analysis shows the uniform distribution of rice husk ash and fly ash particles in the 
aluminium alloy. The microstructure also revealed good retention of rice husk ash and fly ash particles in the matrix.From the Figure 4.1 (a) the fly ash is more as depicted in the form of hollow spheroids. Whereas Rice husk ash in the form of flakes. The reinforcements Rice husk ash and Fly ash are not uniformly distributed due to improper bonding between reinforcements and matrix alloy. From the image 4.1(c) the Rice husk ash is more in the form of flakes and Fly ash in the hollow spheroids is less. In this case the rice husk ash particles are agglomerated on the sides of the composite and dominating fly ash particles this is due to the poor wettability. In this case Figure 4.1(b) it can observe that the Fly ash (hollow spheroids form) and Rice husk ash (Flakes form) are uniformly distributed when the two reinforcements each of $10 \%$ weight are added to matrix alloy are tightly packed due to the surface formed by the combination of reinforcements with the matrix alloy, which ensures good mechanical properties of the resultant hybrid composite (AlSi10Mg + 10\% RHA +10\% FA).

\subsection{Hardness Test (BHN)}

The hardness test results are shown in the below graph for all composite specimens.

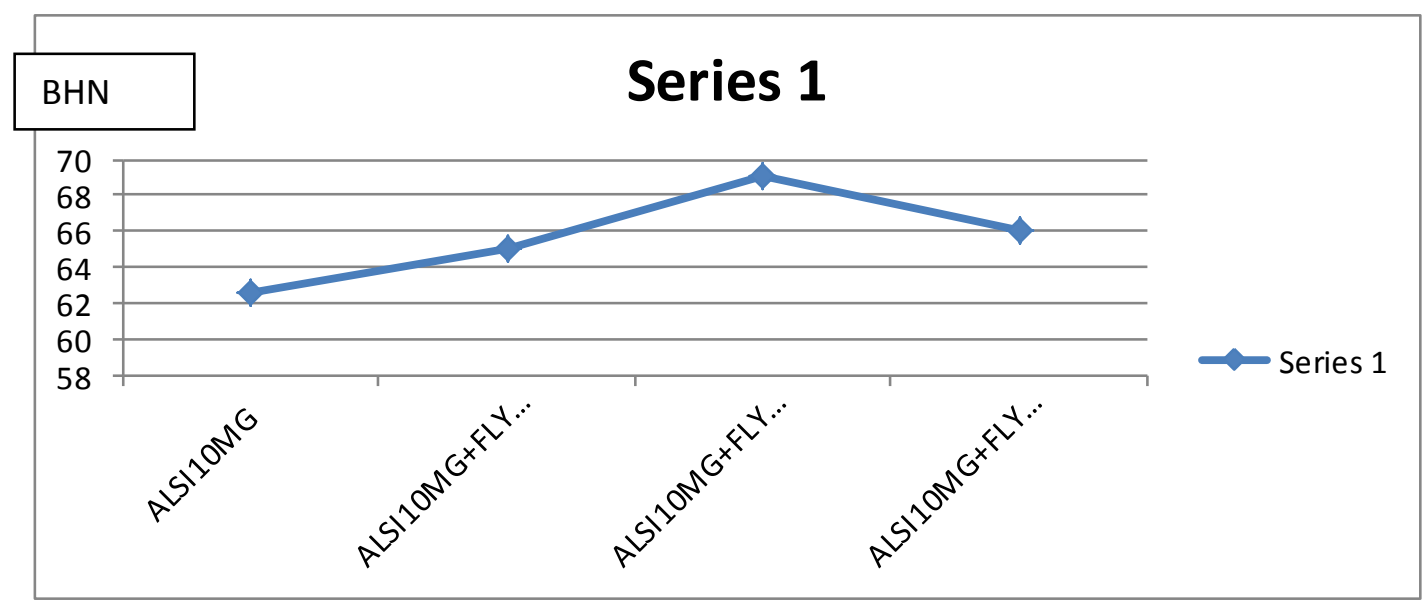

Figure 4.2. Hardness Test Graph

It was observed that the hardness of the composite linearly increasing with the increase in weight fraction of the rice husk ash particles. This occurs due to increases in surface area of the matrix and thus the grain sizes are reduced. The presence of such hard surface area offers more resistance to plastic deformation which leads to increase hardness. The strengthening of the composite can be due to dispersion strengthening as well as due to particle reinforcement. Thus, fly ash as filler in $\mathrm{Al}$ casting reduces cost, decreases density and increase hardness. The reinforcement's fly ash and rice husk ash each of $10 \%$ weight showed maximum hardness.

\subsection{Tension Test}

\subsubsection{Ultimate Tensile Test}

Tensile test was carried out as per ASTM E8 using Instron testing machine. The three specimens with differ different proportions of the reinforcements given the ultimate tensile strength as given below. 


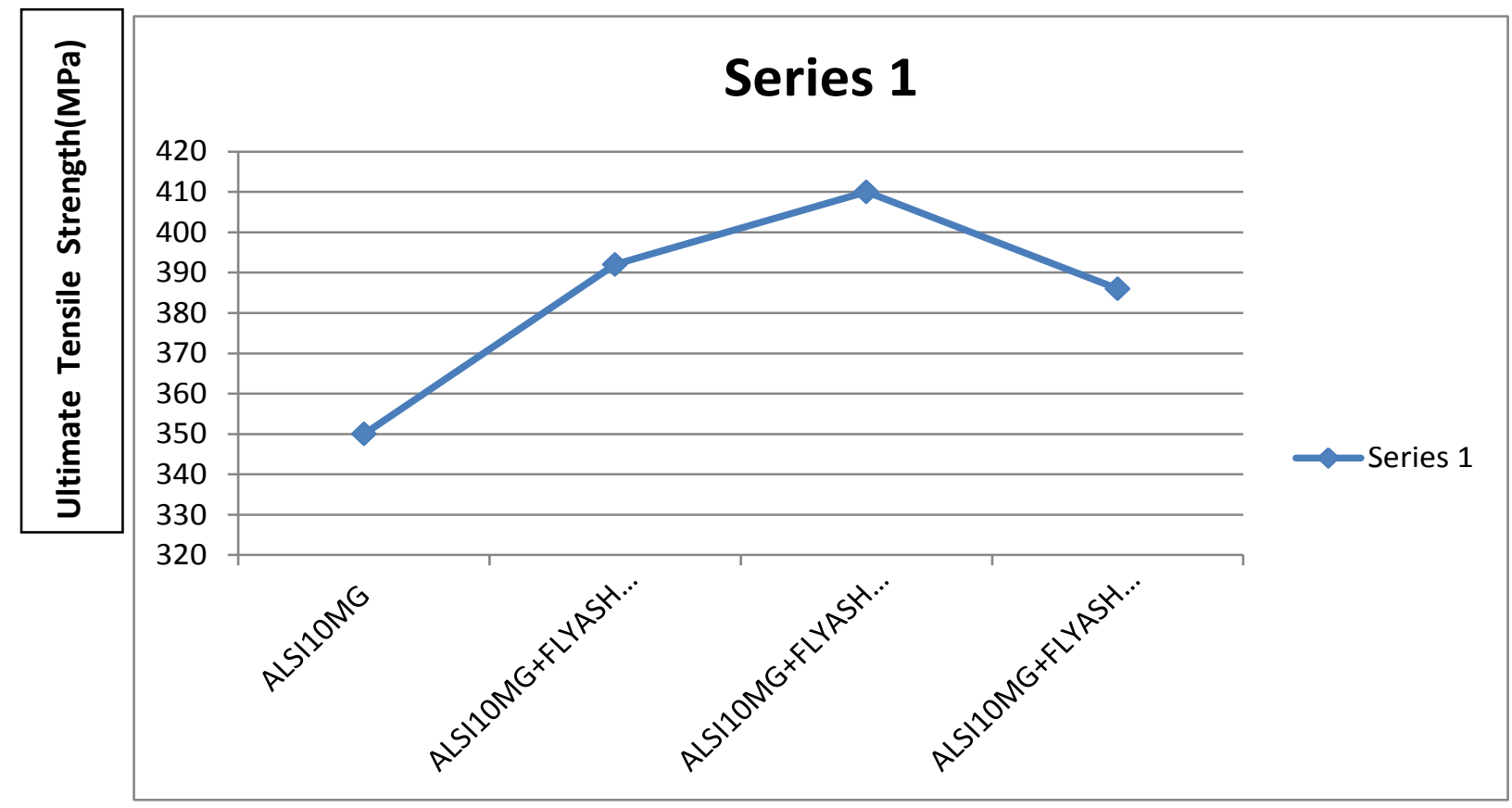

Figure 4.3.1. Ultimate Tensile Strength Graph

From the results it was clear that the rice husk ash and fly ash in equal proportions lead to improvement in the ultimate tensile strength of the composite. The increase in weight percentage of the fly ash itself leads to improve the tensile strength up to a certain weight proportion (i.e., 10\%). It can be inferred that the tensile strength increased with an increase in the weight percentage of rice husk ash but there was a decrease in the tensile strength of the samples with rice husk ash is at $15 \%$ weight proportion. It may due to the poor wettability of the reinforcement with the matrix. But when the rice husk ash and fly ash are taken in equal proportions (i.e., $10 \%$ each) the tensile strength is increased compared to other two proportions (i.e., $15 \% \mathrm{FA}+5 \% \mathrm{RHA}$ and $5 \% \mathrm{FA}+15 \% \mathrm{RHA}$ )

\subsubsection{Percentage Elongation}

The percentage elongation is the measure of ductility of the material. The ductility can be defined as the property of material by which the material can be drawn into a wire under tensile force. The percentage elongation of the three test specimens are given in the graph. 


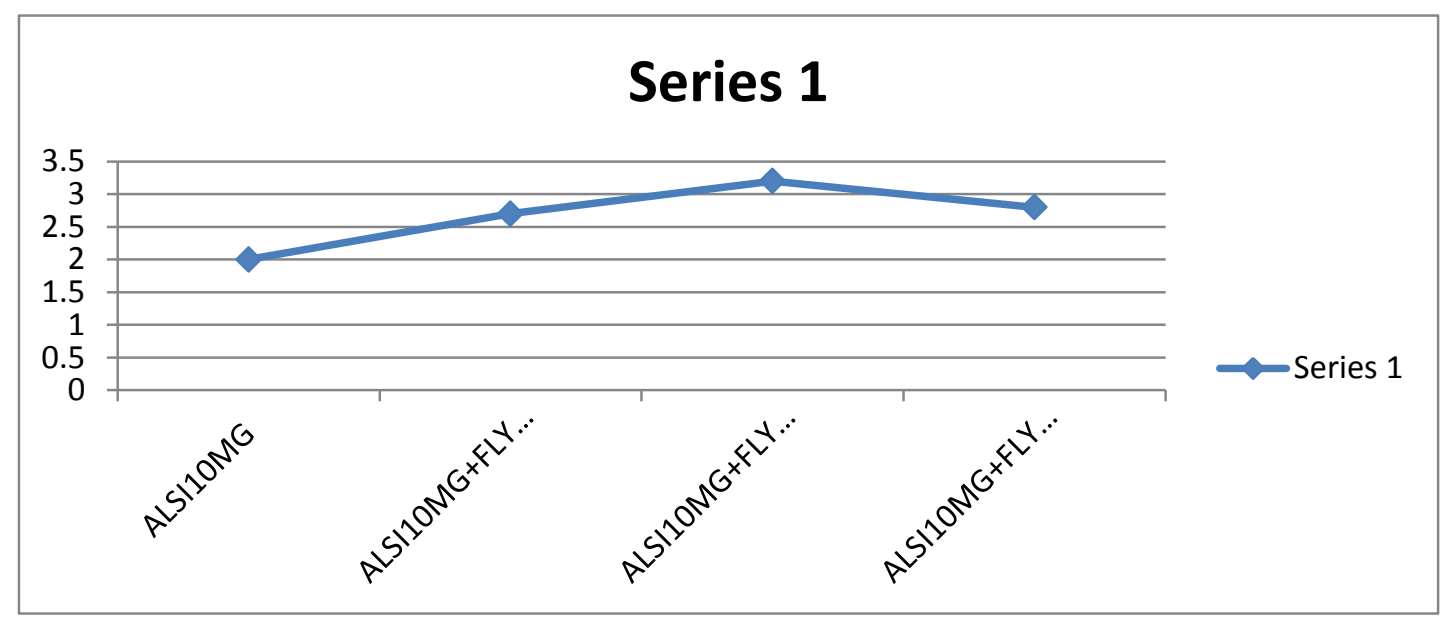

4.2.2. Percentage Elongation Graph

From the above results it is clear that the composite having reinforcements each of $10 \%$ weight has more percentage elongation. The percentage elongation decreases with increase in rice husk ash because the increase in weight \% of rice husk ash increases the hardness and decreases the ductility of the composite which leads to the failure of composite under load.

\section{Conclusions:}

The major conclusions of the present study on microstructure and mechanical properties of the Rice Husk ash and Fly Ash reinforced AlSi10Mg hybrid metal matrix composites are summarized below.

- The micro structures revealed that reinforcements in $10 \%$ each by wt. are distributed uniformly and tightly packed when compared to other combinations of reinforcements probably due to the surface formed by reinforcement combination with the matrix alloy.

- The tensile strength of the composite is found to be decreased when rice husk ash is increased and is maximum when fly ash and rice husk ash are taken each of $10 \%$ weight.

- The percentage elongation is more with decrease in RHA and increase in FA, because increase in the \% of RHA increases the hardness of MMC and leads to failure of MMC under load.

- The Hardness of MMC increased with increased \% of RHA and decreased with increased $\%$ of Fly ash.

- One of the major requirements for uniform distribution of particles in the melt is its wettability. The poor wettability of the phases in the matrix is the major problem at higher weight fraction of reinforcement, due to this problem the strength decreases after certain limit. From this problem we can overcome by adding small amount of Magnesium and by pre heating the composites and the die.

\section{References}

[1] S. D. Saravanana and M. Senthil Kumar, "Effect of Mechanical Properties on Rice Husk Ash Reinforced Aluminum alloy (AlSi10Mg) Matrix Composites", International Conference On design and manufacturing, icondm 2013, procedia engineering, vol. 64, (2013), pp. 1505-1513. 
[2] S. Sarkar, S. Tripathy and S. Mohan, "Effect of Si and Mg Addition on Dry Sliding Wear of Al-Fly Ash Metal Matrix Composite", International Journal of Material and Mechanical Engineering (IJMME), DOI: 10.14355/ijmme.2014.0302.02, vol. 3, no. 2, (2014) May.

[3] H. C. Anilkumar, H. S. Hebbar and K. S. Ravishankar, "Mechanical properties of Fly ash reinforced Aluminium alloy (al6061) composites", International Journal of Mechanical and Materials Engineering (IJMME), vol. 6, no. 1, (2011), pp. 41-45.

[4] S. D. Kene, P. V. Domke, S. D. Deshmukh and R. S. Deotale, "Assessment of Concrete Strength using Fly ash and Rice Husk ash", International Journal of Engineering Research and Applications (IJERA), ISSN: 2248-9622, vol. 1, no. 3, pp. 524-534.

[5] D. Siva Prasad and Dr .A. Rama Krishna, "Fabrication and Characterization of A356.2-Rice Husk Ash Composite using Stir casting technique", International Journal of Engineering Science and Technology, vol. 2, no. 12, (2010), pp. 7603-7608.

[6] V. K. Lindroos and M. J. Talvitie, "Recent advances in metal matrix composites", Journal of Materials Processing Technology, vol. 53, no. 1, (1995), pp. pp. 273-284.

[7] S. Sarkar, S. Sen and S. C. Mishra, "Aluminum - fly ash composite produced by impeller mixing", Journal of reinforced plastics and composites, (2008), pp. 1-6.

[8] U. Rattanasak, P. Chindaprasirt and P. Suwanvitaya, "Development of high volume rice husk ash alumino silicate composites", International Journal of Minerals, Metallurgy, and Materials, vol. 17, no. 5, pp. 654-659.

[9] P. Rohatgi, "Cast aluminum-matrix composites for automotive applications", JOM Journal of the Minerals, Metals and Materials Society, vol. 43, no. 4, (1991), pp. 10-15.

[10] K. K. Chawla, "On the applicability of the "Rule-of-Mixtures" to the strength properties of metalmatrix composites", Revista Brasileira de Física, vol. 4, (1974), pp. 411-418.

[11] J. Narciso, A. Alonso, A. Pamies, C. G. Cordovilta and E. Louis, "Wettability of binary and ternary alloys of the system Al-Si-Mg with SiC particulates”, Scripta Metall, vol. 31, (1994), pp. 1495-1500.

[12] S. M. K. Sudarshan, "Synthesis of fly ash particle reinforced A356 Al composites and their characterization", Materials Science and Engineering, A 480, (2008), pp. 117-124.

[13] A. Swamy, A. Ramesha, G. C. Kumar and J. Prakash, "Effect of Particulate Reinforcements on the Mechanical Properties of Al6061- WC and Al6061-Gr MMCs", Journal of Minerals \& Materials Characterization \& Engineering, vol. 10, (2011), pp. 1141-1152.

[14] B. C. Pai, G. Ramani, R. M. Pillai and K. G. Satyanarayana, "Role of magnesium in cast aluminium alloy matrix composites”, Journal of Materials Science, vol. 30, (1995), pp. 1903-1911-1911.

[15] Mr. Sharanabasappa, R. Patil and Prof B. S. Motgi, "A Study on Mechanical Properties of Fly Ash and Alumina Reinforced Aluminium Alloy (LM25) Composites”, e- ISSN: 2278-1684, p-ISSN: 2320334X, vol. 7, no. 6, (2013) July-August, pp. 41-46.

\section{Author}

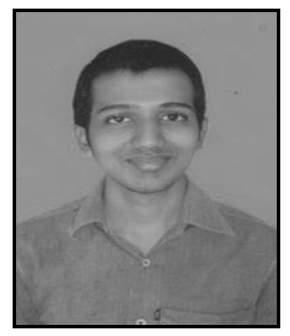

A. P. S. V. R. Subrahmanyam, was born on 28-06-1990.He completed his B.Tech in Mechanical engineering from A.S.R. College of Engineering, Tanuku, Andhra Pradesh, India in the year 2011.He completed M.Tech with Advanced Manufacturing Systems specialization from BVEC, Odalarevu, Andhra Pradesh, India in the year 2014.Presently he is working as Asst.Professor in the Department of Mechanical engineering, B.V.C college of Engineering, Rajahmundry, Andhra Pradesh, India. His interested research areas are Hybrid metal matrix composites, Low cost reinforced metal matrix composites, Material processing and surface engineering. 